\title{
cultura y desarrollo
}

\section{LA TRAYECTORIA DEL DESARROLLO EN AMÉRICA LATINA: UNA PERSPECTIVA CRÍTICA DESDE SU MATRIZ CULTURAL}

Alejandro Estenós Loayza

Desde los inicios de su vida republicana los pueblos latinoamericanos han realizado denodados esfuerzos por ubicarse entre aquellos que llevan el rótulo de modernos y desarrollados. Los reiterados fracasos de estos intentos estuvieron asociados a profundos cuestionamientos sobre la posibilidad y conveniencia de asumir los proyectos de progreso y desarrollo, toda vez que las caracteristicas culturales de esta parte del continente eran muy diferentes a los contextos culturales originarios de dichos proyectos. Desde entonces, en distintos momentos de aguda crisis social en la región se han suscitado acalorados debates en torno a las dificultades culturales de los pueblos locales 
para asumir como propios los procesos de progreso $\mathrm{y}$ desarrollo que traía consigo la modernización occidental. En medio de estas controversias han descollado polarizadas posiciones teóricas y pragmáticas que decodificaban la relación entre modernización, desarrollo y cultura o bien en términos de un excesivo simplismo a-histórico y a-cultural o bien en términos antitéticos e irreconciliables. Desde hace casi dos siglos, estas posiciones han consentido una visión de la propia identidad en términos de inferioridad que necesita - a como dé lugar - del proyecto modernizador o bien, por el contrario, una visión de la identidad esencialmente diferente, y por lo tanto, incapaz de asumir eficazmente cualquier proceso modernizador.

En la actualidad los magros resultados obtenidos por la aplicación de las teorias del desarrollo ultraliberal, así como la conciencia generalizada de la crisis de la modernidad y las profundas transformaciones socioculturales - que a su vez impulsan simultáneamente tanto la globalización del proyecto modernizador como la revalorización de las identidades culturales - han motivado una renovada reflexión académica e institucional que retoma antiguas discusiones sobre la posibilidad y conveniencia de conciliar la identidad cultural latinoamericana con la modernización y el desarrollo.

El presente trabajo tiene como objetivo realizar una sucinta exploración de las principales líneas de reflexión y praxis del desarrollo con relación a la cultura latinoamericana desde sus inicios (allá por la década de los 
cincuenta del siglo pasado), para luego plantear algunas pistas sobre la posibilidad de un desarrollo que reclama una urgente conciliación con dicha identidad cultural, y de ese modo permitir una inserción consciente y crítica en la modernidad.

\section{LA CRISIS DEL DESARROLlO EN EL ÁMBITO DE LA CRISIS DE LA MODERNIDAD}

Sin duda, uno de los proyectos más potentes que ha impulsado la modernidad ha sido el del progreso y el desarrollo. Por ello cuando en la actualidad se evidencia con más fuerza que nunca los sintomas inequivocos de la crisis de la cultura moderna, ${ }^{1}$ también se hace referencia explícita a la crisis que atraviesa el imaginario del desarrollo. Igualmente, cuando se evidencian las negativas consecuencias que ha tenido el proceso de desarrollo en la mayor parte del mundo, también se está criticando la expansión del modelo cultural moderno. Así, en los postulados modernos que sostienen una racionalidad instrumental antes que una racionalidad sustantiva, el imperio de una razón totalitaria, la secularización de los valores, el

1. El cuestionamiento sobre la crisis de la modernidad no es un fenómeno reciente; tiene antecedentes en el siglo XIX cuando se levantan voces de protesta contra las consecuencias del progreso europeo. Tal es el caso de Marx, Weber, Tönies, Simmel, entre otros. Posteriormente, en la primera mitad del siglo XX los devastadores efectos las dos guerras mundiales serán detonantes para nuevos cuestionamientos sobre la modernidad. 
predominio de una ética utilitarista, el dominio prometeico de la naturaleza mediante la ciencia y la técnica, la convicción de una evolución lineal e indefinida, entre otros, encontramos los fundamentos de un desarrollo que ha provocado graves daños -en algunos casos irreversiblesen la realidad humana y su entorno. ${ }^{2}$

La comunidad mundial adquirió una particular sensibilidad de lo anterior cuando empezaron a evidenciarse el deterioro ecológico y medioambiental del planeta en la década de los setenta: destrucción de la capa de ozono, lluvias ácidas, contaminación de mares y rios, infertilidad de la tierra, alteraciones climáticas, extinción de especies animales, polución de las ciudades, calentamiento global, etc. Del mismo modo se hicieron evidentes los daños sociales y culturales causados a la humanidad, tales como el sustancial deterioro de los lazos de integración y solidaridad, los fenómenos de anomia y crisis de identidad, violencia e intolerancia, exclusión y marginación, pobreza y desigualdad, comercialización y explotación del ser humano, relativismo moral y politeísmo axiológico, abstracción y menosprecio de la diversidad cultural, etc. Se ha insistido en que toda esta semiótica social nos estaria ubicando frente a una dramática crisis que cuestiona profundamente el tipo

2. No es nuestra intención negar los positivos logros del desarrollo moderno para el ser humano; de hecho, se han alcanzado avances notables en el bienestar material de al sociedad, pero a costa del menosprecio -cuando no de la negación - de otros aspectos vitales del ser humano. Véase Larrain 1994: 62. 
de civilización construida por el hombre moderno; la crisis de un desarrollo que se constituye como una grave amenaza para su propia existencia.

\section{Crítica a la matriz epistemológica de las TEORÍAS DE DESARROLLO}

Esta constatación de la crisis de la modernidad y el desarrollo está íntimamente asociada a una aguda crítica formulada contra el dispositivo epistemológico de unas ciencias sociales que habrian avalado e impulsado su particular despliegue.

Según se ha argumentado, desde los inicios de la era desarrollista los análisis académicos e institucionales ligados a los diferentes ámbitos de las ciencias sociales ensayaron -desde su particular enfoque disciplinariosofisticadas teorias destinadas a identificar posibles relaciones de causalidad que dilucidaran satisfactoriamente los alcances de los problemas planteados y exploraran sus posibles salidas. Sin embargo, dada la actual complicación de la realidad social, dichos enfoques disciplinarios particulares habrian evidenciado, una vez más, serias limitaciones para hacer inteligible de manera holística la realidad en la que se inscriben los problemas del desarrollo. De este modo, se privilegiaron explicaciones originadas en el ámbito de las ciencias politicas y económicas, y se relegaron a un segundo plano los aportes de otras disciplinas que relevan factores epistemológicos, éticos y culturales. El 
- Alejandro Estenós Loayza -

peligro de esta limitación propia de las ciencias sociales modernas es evidente: instala en el proceso de análisis serios riesgos de reducción y distorsión en las premisas y categorias que generan conocimiento. En ese sentido se denuncia una teoria del desarrollo que en su análisis hace un excesivo énfasis tanto en el terreno político institucional como en el macroeconómico. Consecuentemente se ha planteado la necesidad de integrar orgánicamente en esa teoria la mirada de otras disciplinas sociales que visualicen el problema en su conjunto.

No es este un problema menor, más aún cuando se pretende incorporar a la discusión del desarrollo aspectos sustanciales insuficientemente tratados. Por ello parece pertinente dedicar un espacio de reflexión a la génesis de este sesgo epistemológico que han mostrado las ciencias sociales desde sus inicios.

Con ciertos matices y diferencias, los criticos señalan que la modernidad instala en el pensamiento occidental la idea de una evolución materialista y lineal de la humanidad. En este imaginario la ciencia se convierte en el medio privilegiado para lograr tal propósito, una ciencia renovada en sus principios, independiente de todo prejuicio especulativo y centrada en la investigación científica, cuyo método experimental se erige como el único proceso capaz de generar conocimiento objetivo y verdadero. ${ }^{3}$ En adelante todo

3. Este pensamiento tiene plena correspondencia con los presupuestos positivistas de Comte, considerado el padre de la Sociologia. 
conocimiento que pretendiera tener validez objetiva y universal debia incorporar dicho método a sus procesos de investigación. En su obcecación por adquirir el mismo estatus científico de las ciencias naturales, las ciencias sociales incorporaron dicho método en sus procedimientos, generando con ello dos limitaciones medulares para su desempeño futuro.

En primer lugar, al igualar el estatus epistemológico de las ciencias sociales al de las naturales se comete el error de reificar la realidad humana en sus diferentes expresiones. Como producto de este reduccionismo el ser humano será tomado como objeto de análisis experimental, y se hará violencia sobre sus dimensiones no susceptibles de sometimiento al método científico (desde ahora recluidas al ámbito privado). Como corolario de ello, una nueva racionalidad se impone en la vida social: se trata de la racionalidad formal-instrumental que desplaza a la tradicional racionalidad sustantiva; la primera "[...] es una razón ocupada de [en] analizar, calcular, cuantificar[,] y autoconstruida en el único tribunal de la experiencia. Todo ello en desmedro de su contraparte substantiva donde moran los valores, deseos, utopias, imposibles de articular desde su lógica" (Salvat 1994).

En segundo lugar, las ciencias sociales se especializan en diferentes ámbitos de la realidad. Este proceso supone delimitar un objeto de análisis para cada disciplina haciendo abstracción de las complejas relaciones - tanto internas 
como contextuales - del sujeto ahora convertido en objeto. De este modo, cada disciplina social analizará aspectos especificos y parciales de la realidad social como subsistemas o esferas que progresivamente irán naturalizándose como independientes y autopoiéticas. Esto podría conducir - como de hecho ha sucedido - a privilegiar una sobre las otras de modo arbitrario o, más aun, renunciando a toda referencia objetiva. Aquellas esferas desfavorecidas en este balance serán entendidas como anexas, periféricas $\mathrm{y}$ accidentales a aquella.

En este marco el ser humano pierde su condición de sujeto situado y protagonista de su realidad, para ser determinado y subsumido en aquella fragmentaria estructura externa a su conciencia, sea esta política, económica o social.

Naturalmente, las modernas teorias sociales -entre ellas las de desarrollo y modernización - se han visto afectadas en diferente grado por ambas limitaciones, lo que ha generado una aproximación parcial y distorsionada a la realidad del desarrollo.

Este parece ser un adecuado marco analítico que permite abordar las limitaciones y distorsiones de una teoria desarrollista que propone taxativamente una comprensión del desarrollo sin sujeto $\mathrm{y}$ en términos a-históricos $\mathrm{y}$ a-culturales. 


\section{LA TRAYECTORIA DEL QUEHACER DESARROLLISTA Y SU APROXIMACIÓN A LA CULTURA LATINOAMERICANA}

Brevemente conviene recordar que la problematización del desarrollo surge después de la Segunda Guerra Mundial, cuando el mundo sufrió la doble ordenación de bloques políticos e ideológicos: por un lado, liberalismo y comunismo; por otro, el bloque de paises europeos que necesitaban reconstruirse y el conjunto de naciones -identificado taxativamente como tercer mundo- que necesitaban desarrollarse. Esta necesidad es asumida convenientemente por las potencias hegemónicas, que en adelante impulsarán la reflexión e implementación de vastos planes de desarrollo como medio fundamental para reproducir su exitoso modelo de civilización y, con ello, asegurar poder y hegemonia en la región.

El discurso formal sobre el desarrollo comenzó asi a instalarse en la sociedad mundial, y desde entonces un vasto cuerpo teórico y práctico ha sido producido por las ciencias sociales y los organismos de cooperación internacional creados en Bretton Woods (el Banco Mundial y el Fondo Monetario Internacional). Según Escobar, el discurso y la problematización del desarrollo han operado desde su origen por medio de dos mecanismos principales:

i) la profesionalización de problemas de desarrollo, lo cual ha incluido el surgimiento de conocimientos 
especializados así como de campos para lidiar con todos los aspectos del subdesarrollo (incluyendo el campo en sí del estudio del desarrollo);

ii) la institucionalización del desarrollo, la vasta red de organizaciones antes mencionada. Estos procesos facilitaron la vinculación sistemática de conocimiento y práctica por medio de proyectos e intervenciones particulares. (Escobar 2005)

Dichos mecanismos del quehacer desarrollista - profesionalización e institucionalización - fueron construidos sobre la base de un sistema de conocimiento occidental y de acuerdo con la especificidad ideológica moderna. En otras palabras, se puede decir que toda la práctica y la teoría del desarrollo en el llamado tercer mundo - donde se encuentra América Latina - se asientan irremediablemente sobre la episteme cultural moderna de procedencia europea y norteamericana que acabamos de reseñar.

En este marco revisaremos las teorias de desarrollo aplicadas en Latinoamérica y la relación con su matriz cultural, esquematizadas a partir de los especificos proyectos socioeconómicas que, surgidos en la Europa moderna, se expandieron progresivamente -unos con más éxito que otros - hacia el resto del mundo, donde contamos a América Latina.

Es necesario precisar que estos proyectos socioeconómicos modernos se desprenden de los paradigmas 
sociológicos clásicos postulados por Bajoit, ${ }^{4}$ a saber: del paradigma de integración surge el proyecto por modernización; del paradigma de alineación surge el proyecto por revolución; del paradigma de competencia surge el proyecto ultraliberal; y del paradigma de conflicto surge el proyecto por democracia. ${ }^{5}$

\subsection{TEORÍA DE DESARROLlO POR MODERNIZACIÓN}

El primer intento de la era desarrollista por modernizar América Latina se registrará en los años cincuenta bajo la influencia de la sociologia norteamericana ${ }^{6}$ y de los primeros trabajos de la Comisión Económica para América Latina y el Caribe (CEPAL) con el modelo sustitución de importaciones. El tema del desarrollo se convierte en un problema de ingenieria: "[...] la modernización no es más, entonces, un ajuste con el pasado, sino un dilema de la construcción del

4. Corvalán plantea que toda construcción socioeconómica descansa en uno de los cuatro paradigmas sociológicos clásicos. Ello permite acceder a un cuerpo teórico que permite identificar problemáticas, proponer la manera de abordarlas, y ver claro el marco y lenguaje en el que se expresan tanto el proceso de investigación como las conclusiones, lo que en definitiva ayuda a hacer más inteligible cada uno de los mencionados proyectos (Corvalán 1997).

5. Conviene precisar que si bien esta categorización analitica es sumamente útil para comprender y dilucidar lo esencial de dichos procesos, ella supone a la vez un peligro no menor, pues dado lo complejo de la realidad se corre el riesgo de generalizaciones injustas o categorizaciones rigidas e inflexibles.

6. La influencia de Parsons será decisiva para la categorización y diferenciación entre la sociedad moderna y la sociedad tradicional. 
futuro. La tarea es aplicar el conocimiento cientifico y tecnológico a todas las actividades sociales de tal modo de optimizar el bienestar de todos mediante la maximización de los recursos y la funcionalidad de las estructuras" (Morandé 1987: 19). Se trata, pues, de una propuesta modernizadora decididamente a-cultural y a-histórica, justificada por la supuesta validez natural y universal de sus premisas.

En sus planteamientos, el conocimiento científico induciria el tránsito del modelo societario tradicional hacia el moderno, único camino posible para maximizar las posibilidades de crecimiento económico en vistas a mejorar la calidad de vida de la población. En adelante los planes desarrollistas de modernización impulsarán medidas como el

[...] control del crecimiento demográfico, superación del analfabetismo, migración rural-urbana, integración del migrante campesino a las pautas del comportamiento de la ciudad, cambio de la dependencia paternalista de la autoridad por el sometimiento objetivo a las decisiones de una autoridad impersonal y reglamentada en sus funciones, aplicación de la racionalidad técnica a las decisiones politicas, contribución de las ciencias sociales a la toma de decisiones por parte de la autoridad gubernamental, desarrollo de los sistemas de contabilidad social por medio de indicadores estadísticos permanentes, democratización del acceso a la enseñanza escolar y universitaria, superación del caudillismo y clientelismo politico, organización de las demandas sociales a través 
- Desarrollo y cultura en América Latina -

de la sindicalización y agrupamientos afines, desarrollo del sector industrial y del empleo estable, fomento a la constitución de un mercado interno y sólido, distribución más igualitaria del progreso, distribución de la tierra en el sector agricola, secularización de las creencias acerca del funcionamiento de vida social, de la salud, de la medicina, de las mismas formas de pertenencia a grupos religiosos y muchos otros temas que podriamos mencionar. (Morandé 1987: 19)

En otras palabras, las élites modernizadoras pretendian inducir un radical cambio en la sociedad y cultura latinoamericanas, cambio que permitiera moldearla a imagen y semejanza de las sociedades que ya alcanzaban un desmesurado desarrollo técnico-material. Sin embargo $-y$ pese a los ingentes recursos destinados a este propósito- la mayoría de la población latinoamericana, en especial la rural, no cambió; el intento de secularizar y racionalizar sus valores y creencias produjo más bien un efecto negativo y de cierta aversión hacia los tecnócratas desarrollistas y las élites estatales. ${ }^{7}$ Esto, sumado a los escasos resultados económicos del modelo sustitutivo de importaciones, generará serias críticas al capitalismo latinoamericano, y con ello, evidenciará los primeros signos de crisis en este modelo desarrollista.

7. Esto no significa que dichas poblaciones se mantuvieron culturalmente intactas; en definitiva experimentaron cambios en el ámbito simbólico y social, aunque en nuestra opinión no fueron cambios sustanciales. 


\subsection{TeORÍA DE DESARROLlo POR REVOLUCióN}

Como se sabe, tanto en términos culturales como socioeconómicos los resultados del proceso desarrollista por modernización fueron realmente muy exiguos. ${ }^{8}$ Ello provocaría una aguda crítica al proyecto modernizador por parte de teóricos sociales y políticos de corte marxista y socialista. Así, en el pensamiento de la sociologia comprometida - o, indistintamente, sociologia critica- y en las teorias de la dependencia ${ }^{9}$ y en las antiimperialistas de los años sesenta y setenta, se señala como obstáculo para el desarrollo ya no la mentalidad y la cultura tradicionales de los pueblos, sino factores de política internacional que avalan la explotación sistemática de los paises pobres por parte de los países ricos del hemisferio norte. Según estos teóricos, frente a esta situación de imperialismo y dependencia se haría necesario plantear una revolución que permitiera romper con las estructuras de dominación y saqueo que mantienen las potencias del norte coludidas con las élites de poder local.

A este planteamiento desarrollista subyace una lectura histórica de la realidad cultural de América Latina en términos conflictivos y antitéticos, reduciendo de este modo

8. Una propuesta sobre las razones del fracaso del modelo sustitutivo de importaciones pueden verse con detalle en Skidmore y Meter (1996: 67).

9. Entre sus representantes más importantes podemos mencionar a Fernando Enrique Cardoso, Theotonio Dos Santos, André Gunder Frank, Ruy Mauro Marini, y Enzo Faletto, entre otros. 
toda apreciación vital y estética de su especificidad cultural a un mero subproducto de las relaciones económicas y de poder.

Esta corriente de desarrollo termina reproduciendo su propia crítica al proyecto modernizador, pues cambia la supuesta neutralidad valorativa de los discursos científicos y técnicos modernistas por la explícita adhesión al discurso ideológico-politico de corte socialista y marxista, lo que deja de lado las consideraciones histórico-culturales especificas de esta parte del continente (Morandé 1987: 61).

\subsection{TeOría de desarrollo NEOLIBERAL}

A lo largo de tres décadas América Latina había experimentado ya el fracaso del proyecto nacionalistamodernista, en primera instancia, y posteriormente el del marxista-socialista: reformas agrarias incompletas e ineficientes, quiebra del modelo de industrialización por el de sustitución de importaciones, incompetencia y desmedida corrupción del aparato burocrático del Estado, resistencias de los viejos poderes oligárquicos, constantes interrupciones militares en la democracia, aumento de la pobreza y la exclusión, prejuiciosa comprensión de su base cultural son algunas de sus evidencias. Todo ello colocaba a las naciones latinoamericanas peligrosamente cerca de una crisis inmanejable.

Pese a los esfuerzos de las élites estatales, esta finalmente se produjo al despuntar la década de los ochenta, 
asociada a problemas financieros y económicos de alcance internacional. Ello fue ocasión para que resurgiera la doctrina económica liberal, que radicalizada en sus presupuestos $^{10}-\mathrm{y}$ denominada en adelante neoliberalllegaria a tener amplia aceptación en América Latina durante la década de los ochenta y noventa.

Bajo sus presupuestos, el mundo es concebido como un gran mercado cuyo único criterio de inclusión/exclusión es la rentabilidad económica. En la nueva economía global, las fuentes de la productividad y competitividad dependen fundamentalmente de la capacidad de generar conocimiento y procesar eficazmente la información, lo cual depende, a su vez, de la capacidad cultural y tecnológica de las personas, empresas y naciones (Castell 1999: 3). Se actualiza, pues, el principio liberal que potencia la capacidad individual para integrarse al mercado como el único medio seguro para alcanzar el bienestar colectivo.

En consonancia con ello, el neoliberalismo exhibe una aparente posición paradójica frente a la tradición y diversidad cultural. Por un lado, y en consonancia con la

10. Entre los intelectuales y pensadores que más han influido en esta escuela se puede mencionar al filósofo de la ciencia Karl Popper, quien inspira el individualismo metodológico como estandarte frente a las sociedades totalitarias; a Robert Nozick y quienes defienden la libertad del individuo frente a cualquier colectivismo; finalmente, a Friedrich Hayek, quien hace una defensa cerrada del mercado autorregulado frente al Estado benefactor y su idea de justicia social. 
premisa de la elección racional individual según preferencias subjetivas, se muestra tolerante frente a las expresiones culturas locales con las que cualquier individuo es libre de identificarse y vivir en su ámbito privado. Sin embargo, en el ámbito público toda expresión cultural debe respetar e incorporarse al orden social regulado por el mecanismo de mercado, que supone de antemano la suscripción de unos valores secularizados. Se trata de la versión ultraliberal de un proyecto homogenizador de la cultura que hace abstracción de la particularidad histórico-cultura de la región latinoamericana.

Es importante señalar que este proceso fue posible gracias al espacio que la sociologia latinoamericana cedió en favor del predominio y naturalización de la economía. En efecto, después del fracaso de la sociologia comprometida y su excesiva politización, el problema del desarrollo fue visto como un problema técnico que, si bien competía a todas las ciencias sociales, solo a la economía le era posible enfrentar por haber encontrado el instrumental necesario para manipularlo correctamente (Morandé 1987: 62).

\subsection{TeORÍA DE DESARROLlo POR DEMOCRACIA}

Durante la década de los noventa las nefastas consecuencias del modelo de desarrollo neoliberal generan una corriente de agudas críticas desde diferentes sectores académicos e institucionales, entre ellos, los teóricos de la democracia. Estos denuncian que los teóricos políticos 
liberales habrian reducido taxativamente la idea de democracia a su dimensión formal-procedimental, a un conjunto de reglas (instituciones) y normas que regulan el conflicto politico y social al interior de la sociedad, haciendo con ello excesiva abstracción de las problemáticas condiciones económicas, sociales y culturales en las que se inserta.

Frente a ello, y convencidos de la intima relación existente entre democracia y desarrollo, dichos teóricos vienen insistiendo en una serie de reformas cuyo principal propósito es recrear una democracia en la que todo ciudadano tendria reales posibilidades para desarrollarse plenamente. Dichas propuestas parecen coincidir en el papel protagónico que juega la sociedad civil en este proceso. Por ello se insiste en la necesidad de diseñar mecanismos de participación y control social, no solo en el ámbito político sino también en el económico, en el social y en el cultural. En ese sentido se ha señalado la importancia de resignificar el ámbito público como un espacio de libre deliberación sobre asuntos que son de competencia de todos los ciudadanos y no solo de las élites politicas (Cunill 1995: 24-25). Ampliada asi la concepción de lo público, se trataría entonces de recuperar la función de control y crítica que le compete a la sociedad civil sobre los asuntos de interés general para hacer que el Estado y el mercado realmente dirijan sus esfuerzos al interés de todos.

Según estos teóricos, los espacios públicos de deliberación civil resultan especialmente interesantes dada la 
emergencia de la pluralidad y diversidad cultural ocurrida desde los años ochenta. La idea es que el ámbito democrático puede ayudar a conciliar y mediar los conflictos y diferencias que necesariamente genera una configuración social y cultural tan heterogénea como la que caracteriza a Latinoamérica. Precisamente, la emergencia de esta heterogeneidad sociocultural sería consecuencia de la pérdida de relevancia de las instituciones democráticas que, a su vez, seria fruto de las politicas de desmantelamiento y reajuste del Estado exigidas por la globalización económica financiera.

Producto de esto habrian surgido en Latinoamérica una infinidad de movimientos con variados carices identitarios que no son ya pasivos o reactivos como antaño, sino que se organizan alrededor de movimientos sociales que demandan activamente al Estado - a veces en forma violentareconocimiento y reivindicaciones sectoriales (Grzybowski 2004: 53). A los movimientos y organizaciones tradicionales - como grupos sindicales y campesinos- se han sumado novedosas formas de asociación como movimientos populares, asociaciones vecinales, centros de defensa comunal, clubes de madres, casas de la cultura, centros de defensa de los derechos humanos, de derechos de la mujer, de derechos de grupos étnico-raciales, grupos ambientalistas, grupos de minorias sexuales y muchos más.

Este proceso de ampliación del espacio de participación social no estaria exento de lucha y conflicto; por el contrario, 
estos serian condición necesaria para lograrlo. La experiencia histórica asi lo habría demostrado: las grandes conquistas de derechos sociales y politicos han sido posibles gracias a las luchas y conflictos generados por la movilización social.

Es importante señalar que estas teorias sociales recibieron muchas criticas, especialmente después de los graves incidentes ocurridos en países como Ecuador, Bolivia y Perú, en que grandes movimientos étnico-raciales generaron una importante desestabilización social y politica que en la última década amenazó seriamente su gobernabilidad. Las criticas apuntan a que una excesiva exacerbación de los movimientos sociales -en especial los identitarios- genera profundas dificultades para consensuar la idea de un interés público, base de toda construcción democrática.

En esa línea, resulta interesante el pensamiento del sociólogo venezolano E. Lander, quien - a su pesar - señala limites intransitables hacía el imaginario democrático:

La posibilidad de la construcción (democrática) de un consenso en torno al interés público es remota en contextos de extremada jerarquización social y profunda heterogeneidad cultural, como la existente en América Latina. Si la idea de una comunicación horizontal y democrática ha de ser algo más que una abstracta declaración de principios, las propuestas en torno a la reconstitución de las relaciones entre Estado y sociedad deben asumir este problema medularmente. (Lander 1998: 480-481) 
La única salida para aligerar este dilema sería el establecimiento de acuerdos mínimos - mediante una negociación no exenta de conflicto- entre los múltiples intereses de las organizaciones sociales y grupos identitarios culturales.

Reseñado esto, debemos señalar que el despliegue teórico y práctico de las teorias de desarrollo por democracia ha mostrado graves falencias en el intento de articularse con la dimensión humana de la cultura y su especifica trayectoria histórica en América Latina. Por un lado, las consideraciones ético-normativas generan las siguientes dudas e interrogantes: ¿existen limites a la democracia?; de ser así, ¿cuál es el fundamento para dichos limites?; ¿la mayoria o el consenso minimo pueden ser un fundamento adecuado para la democracia?; ¿qué pasa cuando la democracia atenta contra la misma democracia, esto es, cuando la mayoria decide en contra de la misma democracia? Por otro lado, las consideraciones histórico-culturales generan otro tipo de dudas y preguntas: ¿existe realmente una extremada heterogeneidad cultural en América Latina?; ¿no cuenta para nada el legado histórico y cultural común?; ¿realmente no hay posibilidad de concebir una matriz cultural unitaria que al mismo tiempo tolere eficazmente la diversidad?; ¿se puede consolidar una democracia prescindiendo de una lectura serena y objetiva de la trayectoria histórica de América Latina?

Respecto al primer orden de preguntas, estas evidencian la necesidad de un fundamento ético sólido y al mismo 
tiempo universal para hacer viable la democracia. La idea es hacerlo de tal modo que se puedan superar las limitaciones de una tesis rousseauniana que parte de la infalibilidad de la voluntad general, que termina por erigir el consenso relativista como pauta de lo bueno, lo justo y lo verdadero dentro de un marco de negociaciones de economía y poder.

Respecto al segundo orden de preguntas, ellas evidencian la necesidad de valorar adecuadamente la trayectoria histórica de América Latina para apelar, en medio de la actual fragmentación y división social, a una matriz cultural común al tiempo que diversa, susceptible de ser recreada en categorias conciliadoras y reconciliadas.

Luego de este recorrido analítico verificamos que se puede distinguir claramente el carácter a-histórico y a-cultural de las tres primeras teorias. La última teoria, por su parte, la de los movimientos sociales, pese a la pretensión de recuperar la pluralidad de las identidades culturales y sociales como condición necesaria para llevar a cabo cualquier proyecto de desarrollo, termina exacerbando al extremo las diferencias socioculturales latinoamericanas al punto que hace casi imposible consensuar el interés nacional, requisito fundamental para impulsar el desarrollo por democracia. 


\section{Hacia una Comprensión del DeSARRollo DESDE LA PERSPECTIVA DE LA CULTURA LATINOAMERICANA}

En la última década es posible visualizar una América Latina dividida -en algunos casos antagónicamente- en torno a los modelos de desarrollo neoliberal y por democracia, y que además viene recibiendo el creciente influjo de la critica postestructuralista que subraya el papel fundamental que poseen el lenguaje y los significados en la construcción del sujeto y de la realidad social. Al ocaso de la razón sucede la incapacidad del sujeto para producir ideas y discursos; por el contrario, él es producido e interpelado por discursos que lo constituyen como sujeto. Dado que existe una vasta polifonia de discursos, entonces es evidente que existe una multiplicidad de sujetos y realidades sociales (Vattimo 1990).

En este marco de transformación cultural -consecuencia, en parte, de la crisis de la modernidad- se cuestiona radicalmente la idea del progreso y desarrollo moderno que consideraba como naturalmente bueno todo aquello que mejorase las condiciones materiales de la vida del ser humano. Ahora el desarrollo es sometido a juicios ecológicos, sociales e identitarios, y es deseable siempre y cuando no destruya la naturaleza, no atente contra la calidad de vida humana y respete la diversidad de las identidades sociales y culturales. 
En consonancia con la tendencia cultural de estos últimos años se ha generado una gran producción intelectual que pretende recuperar y reivindicar la centralidad del ser humano, la naturaleza y la identidad cultural de los pueblos en todo proceso de desarrollo. Tenemos, por ejemplo, el paradigma del desarrollo humano, auspiciado por el Programa de las Naciones Unidas para el Desarrollo, la teoria del desarrollo sostenible, propuesta por los grupos de protección medioambiental, el enfoque de necesidades, el neoestructuralismo de la Cepal (Sunkel 1990), la teoría del postdesarrollo (Escobar 2005), la propuesta del capital social (Diaz-Albertini 2003), la teoría de las modernidades múltiples (Haberlas 1990), entre otras. Si bien esta producción revisionista ha tenido el inobjetable mérito de aportar claves para una intelección más amplia del proceso de desarrollo, creemos que aún persiste inalterable en ellas el núcleo de las limitaciones epistemológicas previamente reseñadas.

Asi, pues, la pretensión de recuperar al sujeto como protagonista y finalidad del desarrollo sigue fundamentada en una "metafísica de la subjetividad en la cual el sujeto y su razón se autonomizan de toda referencia a alguna objetividad o trascendencia" (Salvat 1994: 8). Con ello, lejos de presenciar el resurgir del sujeto en toda su complejidad, se asiste a su disolución en multiplicidad de discursos - tanto del actor como del teórico desarrollista- que no tienen cómo ser verificados en la realidad. De este modo las consideraciones ecológicas, sociales y culturales carentes de una 
adecuada fundamentación antropológica corren el riesgo de ser radicalizadas unilateralmente prescindiendo de una visión ordenada, unitaria e interdependiente de la realidad humana. Como corolario, la posibilidad de una eficaz ética intercultural sobre la cual se construya un diálogo se reduce a procesos de negociación política, en los cuales las asimétricas relaciones de poder siempre implicarán desarrollos sociales injustos y denigrantes para los más débiles.

Pese a ello, creemos que la insistencia que se viene dando en ciertos ámbitos de las ciencias sociales por recuperar al sujeto es la manera más pertinente de superar las limitaciones gnoseológicas antes planteadas en el ámbito del desarrollo. ${ }^{11}$ Sin embargo sostenemos que para hacer realmente efectivo el retorno del sujeto en dichas teorias tal vez sea oportuno dar un paso más allá: pasar del plano hermenéutico al ontológico para reconocer al sujeto del desarrollo no como un mero individuo racional, sino como persona, lo que supone, en palabras de Pedro Morandé, reconocer

[...] el fenómeno humano en su totalidad e incluir y destacar $[\ldots]$ las preguntas metafisicas que el sujeto humano, esto es, la persona, plantea en relación a su ser y su destino. En ese sentido, la esencial referencia de la

11. En este sentido se viene revalorizando el pensamiento de antiguos pensadores como Mead o Simmel, y de otros más recientes como Habermas, Foucault, Giddens, Taylor o Touraine (Bajoit 2003: 28). 
cultura "a lo humano" en cuanto tal, hace que se plantee que la cultura no puede ser reducida al ámbito de las "instituciones" o "sistemas" pues la cultura no se constituye por el criterio de funcionalidad, sino por una presencia óntica - que no es sino la persona-. (García Quesada 2007: 65)

A su vez, desde esa perspectiva de sujeto situado tal vez se pueda reconocer que la matriz cultural latinoamericana -en especial, las realidades rurales - se ha preservado relativamente de los mecanismos abstractos y racionalizantes que porta la modernidad ilustrada, lo que supone una matriz cultural identitaria en la que los valores - plano axiológico- aún están arraigados y articulados con el "mundo de la vida" (Cousiño 1990), la cual, en medio de una gran diversidad cultural, mantiene como núcleo cohesionador una religiosidad cristiana no exenta de superposiciones y sincretismos, y sujeta además a un acelerado proceso de cambios. Tal vez desde esta mirada se pueda repensar el imaginario de un desarrollo latinoamericano adecuadamente articulado con el reconocimiento de un sujeto situado, el cual no es otro que la persona humana, portadora de una particular matriz cultural, unitaria y plural a la vez. 


\section{Bibliografía}

Arocena, J.

1989 El desarrollo local: un desafío contemporáneo.

Montevideo: Taurus.

Bajoit, G.

2003 Todo cambia. Santiago de Chile: LOM.

Beck, U.

1998 ¿Qué es la globalización? Falacias del globalismo.

Respuestas a la globalización. Barcelona: Paidós.

Brunner, J.

2001 Modernidad: centro y periferia. Claves de lectura.

Santiago de Chile: CEP, Estudios Públicos n. ${ }^{\circ} 83$.

Carriquiry, G.

2005

Una apuesta por América Latina. Buenos Aires:

Sudamericana.

Castell, M.

1999 «Globalización, identidad y estado». En: Temas de desarrollo sustentable. Santiago de Chile:

Programa de las Naciones Unidas para el

Desarrollo. 
Corvalán, J.

I997

«El paradigma de lo social y sus concepciones». Revista de Estudios Sociales, n. ${ }^{\circ}$ 92, trimestre 2, 9-6o.

Cousiño, C. 1990 Razón y ofrenda. Ensayo en torno a los límites y perspectivas de la sociología en América Latina. Santiago de Chile: Pontificia Universidad Católica de Chile.

Cunill, N. 1995

«La rearticulación de las relaciones Estadosociedad: en búsqueda de nuevos sentidos». CLAD Reforma y Democracia, n. ${ }^{\circ}$, Caracas.

Díaz-Albertini, J.

2003 «Capital social, organizaciones de base y el Estado: Recuperando los eslabones perdidos de la sociabilidad». En: Capital social y reducción de la pobreza en América Latina y el Caribe. Santiago de Chile: Comisión Económica para América Latina y el Caribe.

Escobar, A.

2005 «El postdesarrollo como concepto y práctica social». En: Daniel Matto (coord.). Políticas de economía, ambiente y sociedad en tiempos de globalización. Caracas: Facultad de Ciencias Económicas y Sociales de la Universidad Central de Venezuela. 
García Quesada, A.

2007 La fe y la cultura en el pensamiento católico latinoamericano. Arequipa: Universidad Católica San Pablo.

Gissi, J., J. Larraín y F. Sepúlveda

1995 Cultura e identidad en América Latina. Santiago de Chile: Instituto Chileno de Estudios Humanísticos.

Grzybowski, C.

2004 «Democracia, sociedad civil y política en América Latina». En: Programa de las Naciones Unidas para el Desarrollo 2004.

Habermas, J. 1990 La unidad de la razón en la multiplicidad de sus voces en el pensamiento postmetafísico. Madrid: Taurus.

Hayek, F. 1982 «Los principios de un orden social liberal». Revista de Estudios Públicos, n. ${ }^{\circ} 32$.

Hervé, C. 1988 Madrid. Evangelio y culturas. Desde León XIII a Juan Pablo II. Madrid: Edicep.

Kliksberg, B.

2000 Capital social y cultura: claves estratégicas para el desarrollo. Buenos Aires: Fundación Felipe Herrera-Universidad de MarylandFondo de Cultura Económica. 
Kliksberg, B. y L. Tomassini

$2000 \quad$ «El rol del capital social y de la cultura en el proceso de desarrollo». En: Kliksberg 2000.

Lander, E.

2003 La colonialidad del saber: eurocentrismo y ciencias sociales. Perspectivas Latinoamericanas. Buenos Aires: Facultad Latinoamericana de Ciencias Sociales.

Larraín, J. 1994 «La identidad Latinoamericana: teoría e historia». Revista de Estudios Públicos, n. ${ }^{\circ} 55$.

1996a Modernidad, razón e identidad en América Latina. Santiago de Chile: Andrés Bello.

I996b «Postmodernismo e identidad latinoamericana». Revista del Centro de Ciencias del Lenguaje, $n .^{\circ} 13-14$, enero-diciembre.

2005 ¿América Latina moderna? Globalización e identidad. Santiago de Chile: LOM.

Lander, E. 1998 «Límites actuales del potencial democratizador de la esfera pública no estatal». En: Luis Carlos Bresser y Nuria Cunill. Lo público no estatal en la reforma del Estado. Caracas: Clad-Paidós.

Methol Ferré, A.

198I El resurgimiento católico latinoamericano. Bogotá: Consejo Episcopal Latinoamericano. 
Morandé, $P$.

1987 Cultura y modernización en América Latina. Madrid: Encuentro.

Peyser, A.

2003 Desarrollo, cultura e identidad. El caso del mapuche urbano en Chile. Lovaina: Université Catholique de Louvain.

Programa de las Naciones Unidas para el Desarrollo 2002 Nosotros los chilenos: un desafío cultural. Vol. I. Santiago de Chile: LOM.

2004 La democracia en América Latina. Contribuciones para el debate. Lima: Programa de las Naciones Unidas para el Desarrollo

Polanyi, K.

1947 La gran transformación. Los orígenes políticos y económicos de nuestro tiempo. Buenos Aires: s. d.

Rabotnikof, N.

2001 «La caracterización de la sociedad civil: perspectiva de los bancos multilaterales de desarrollo». Nueva Sociedad, n. ${ }^{\circ}$ 171, enero-febrero.

Rist, G. 2000 «La cultura y el capital social: ¿̇cómplices o víctimas del desarrollo?». En: Kliksberg 200o: 49.

Salvat, P.

1994 «Más sobre la dialéctica modernidad / modernización». Revista de Trabajo Social. S. d. 
Skidmore, T. y S. Meter

1996 Historia contemporánea de América Latina:
América Latina en el siglo XX. Barcelona:
Crítica.

Smith, A.

1985 Investigación de la naturaleza y causas de las riquezas de las naciones. Buenos Aires: Fondo de Cultura Económica.

Stiglitz, J.

1998 «Más instrumentos y metas más amplias:

desde Washington hasta Santiago de Chile».

Desarrollo Económico, vol. 38, n. ${ }^{\circ}$ isı.

Sunkel, O.

1991 El desarrollo desde dentro, un enfoque neo estructuralista para América Latina.

México D. F.: Fondo de Cultura Económica.

Tomassini, L.

2000 «El giro cultural de nuestro tiempo».

En: Kliksberg 2000.

Touraine, A.

1969 La sociedad postindustrial. Barcelona: Ariel.

Vattimo, G.

1990 La sociedad transparente. Barcelona: Paidós. 